\title{
Urinary bladder paraganglioma metastatic to the lung in a patient with SDHB gene mutation: A case report
}

\author{
Chinelo P. Onyenekwu, Kenneth A. Iczkowski, Yuri Sheinin* \\ Department of Pathology, Medical College of Wisconsin, Milwaukee, USA
}

Received: December 29, 2020

Accepted: April 17, 2021

Online Published: April 29, 2021

DOI: $10.5430 /$ crcp.v8n1p5

URL: https://doi.org/10.5430/crcp.v8n1p5

\begin{abstract}
Introduction: Paragangliomas represent tumors originating from the neural crest. Most of them are benign and arise from various locations in the body. Extra-adrenal paragangliomas develop as sporadic cases in most settings or as part of hereditary familial syndromes in about one-quarter of all cases, whereby succinate dehydrogenase subunit B (SDHB) gene mutations are associated with an aggressive clinical disease course of pheochromocytomas/paragangliomas.

Methods: We present a 41-year-old male former smoker with a history of a growing right upper lung nodule on chest imaging. He had no cough or respiratory symptoms. Twenty-seven months prior, the patient underwent a cystoprostatectomy due to paraganglioma of the bladder. Genetic testing identified a pathogenic mutation in SDHB gene, c.166_170delCCTCA (p.Pro56Tyrfs*5). He underwent a wedge resection of the lung nodule.

Results: Sectioning of the lung wedge revealed a well-circumscribed, firm tan nodule. Microscopically there were nests of large neoplastic cells with round nuclei and eosinophilic granular cytoplasm. Tumor cells were positive for synaptophysin and chromogranin and negative for pan-cytokeratin. S-100 protein highlighted sustentacular cells. Morphologically, the pulmonary neoplasm was similar to the primary tumor of the bladder. These features are consistent with a bladder paraganglioma metastatic to the lung, in a background of a hereditary paraganglioma syndrome.

Conclusion: Extra-adrenal paraganglioma occurring in a setting of hereditary paraganglioma syndrome has a high risk of metastasis. Lifelong surveillance even after prompt resection of the primary tumor with negative margins is required to ensure early detection of metastasis and prevent complications associated with it.
\end{abstract}

Key Words: Heredofamilial, Metastasis, Paraganglioma, Pheochromocytoma, Succinate dehydrogenase B gene

\section{INTRODUCTION}

Paragangliomas represent uncommon tumors of chromaffin cell origin arising from the sympathetic and parasympathetic ganglia in any location in the body and are typically amenable to surgical resection. The diagnosis of these tumors remains challenging due to the absence of definitive presenting signs and symptoms in patients. Most paragangliomas occur in the head and neck region. The number of metastases (though generally rare) is increasing in tumors exceeding $5 \mathrm{~cm}$ in diameter size at diagnosis and are associated with succinate dehydrogenase B (SDHB) gene mutation. Nonetheless, the number of cases with distant metastases is few and far between. ${ }^{[1]}$ We hereby present the rare case of a patient developing pulmonary metastases originating from a bladder paraganglioma, occurring less than one year following radical cystoprostatectomy for the primary tumor, with negative surgical margins and a concise review of the existing literature on this topic.

*Correspondence: Yuri Sheinin; Email: ysheinin@mcw.edu; Address: Department of Pathology, Medical College of Wisconsin, Milwaukee, USA. 


\section{Case presentation}

A 41-year-old male former smoker with 3.75 pack years, who was 3.25 years post smoking cessation presented with urinary frequency and left lower abdominal pain for several weeks. He had significant migraines, nausea, vomiting, and hypertension. Blood normetanephrine was $1,047 \mathrm{pg} / \mathrm{mL}$ (reference value $<145 \mathrm{pg} / \mathrm{mL}$ ). Urinalysis was significant for $2+$ proteinuria, leucocytes, bacteria and microscopic hematuria, with a negative urine culture. Abdominopelvic computerized tomography scans without contrast performed a month prior had revealed a soft tissue mass in the left pelvis, appearing to be originating from the bladder wall, with mass effect on the distal ureter, and causing moderate to severe hydronephrosis and hydroureter. Cystoscopy and biopsy were performed, in addition to left ureteral stent placement. Biopsy results confirmed the diagnosis of a paraganglioma, whereby a positron emission tomography scan demonstrated the absence of metastatic disease. However, it showed an interval growth of the bladder mass. Genetics consultation and testing showed a pathogenic mutation in the SDHB gene, c.166_170delCCTCA (p.Pro56Tyrfs*5). The patient underwent a radical cystoprostatectomy with a Y-shaped neobladder. Pathology showed a $5.8 \mathrm{~cm}$ paraganglioma of the bladder with invasion into perivesical tissue. The resection margins and all lymph nodes were negative, but the tumor showed perineural and lymphovascular invasion and was staged as pT3bNOMx (see Figure 1).

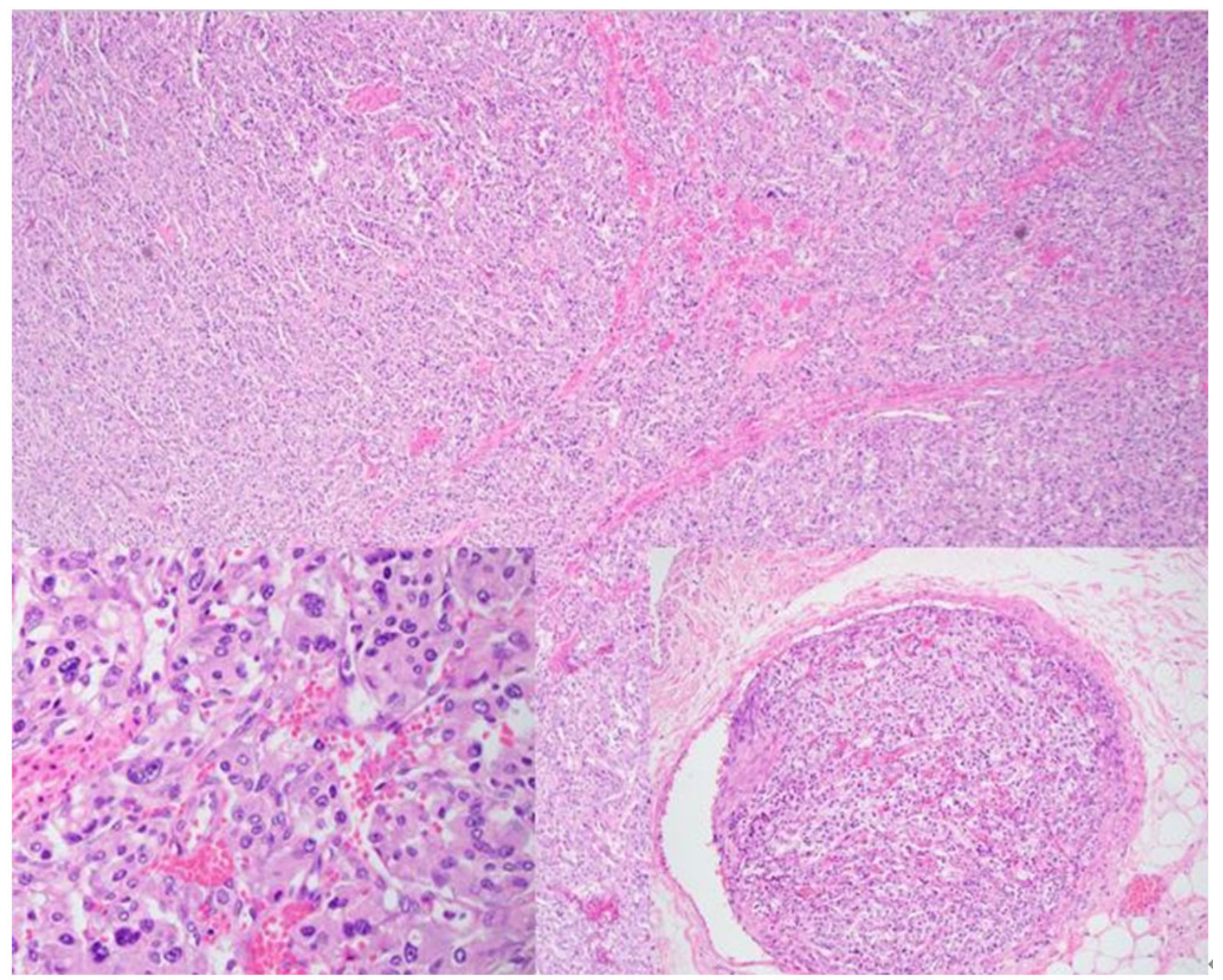

Figure 1. Primary paraganglioma in the urinary bladder, $\mathrm{x} 4$ (left inset, $\mathrm{x} 20$; right inset-lymphovascular invasion)

The patient was monitored with an annual follow-up evaluation, including radiologic surveillance, as well as an assessment of biochemical tumor markers. Radiologic imaging showed a new small indeterminate nodule in the right upper lung four months after the cystoprostatectomy. Twenty- seven months after the cystoprostatectomy, with an interval increase in the lung nodule size, although the patient showed no signs or symptoms of respiratory disease, a wedge resection was performed. Pathologic evaluation of the lung wedge specimen revealed a well-circumscribed, $3 \mathrm{~mm}$ firm 
tan nodule. Histology demonstrated nests of large neoplastic cells with predominantly round nuclei and eosinophilic granular cytoplasm. Further characterization of these cells by immunohistochemistry showed them to be positive for synaptophysin and chromogranin (see Figure 2). The tumor cells were negative for pan-cytokeratin which highlighted background alveoli and pneumocytes. S-100 protein high- lighted sustentacular cells. Morphologically, the pulmonary neoplasm was similar to the prior tumor of the bladder, however it demonstrated minimal nuclear pleomorphism. These features are consistent with a paraganglioma of the bladder metastatic to the lung, in a background of a hereditary paraganglioma syndrome.

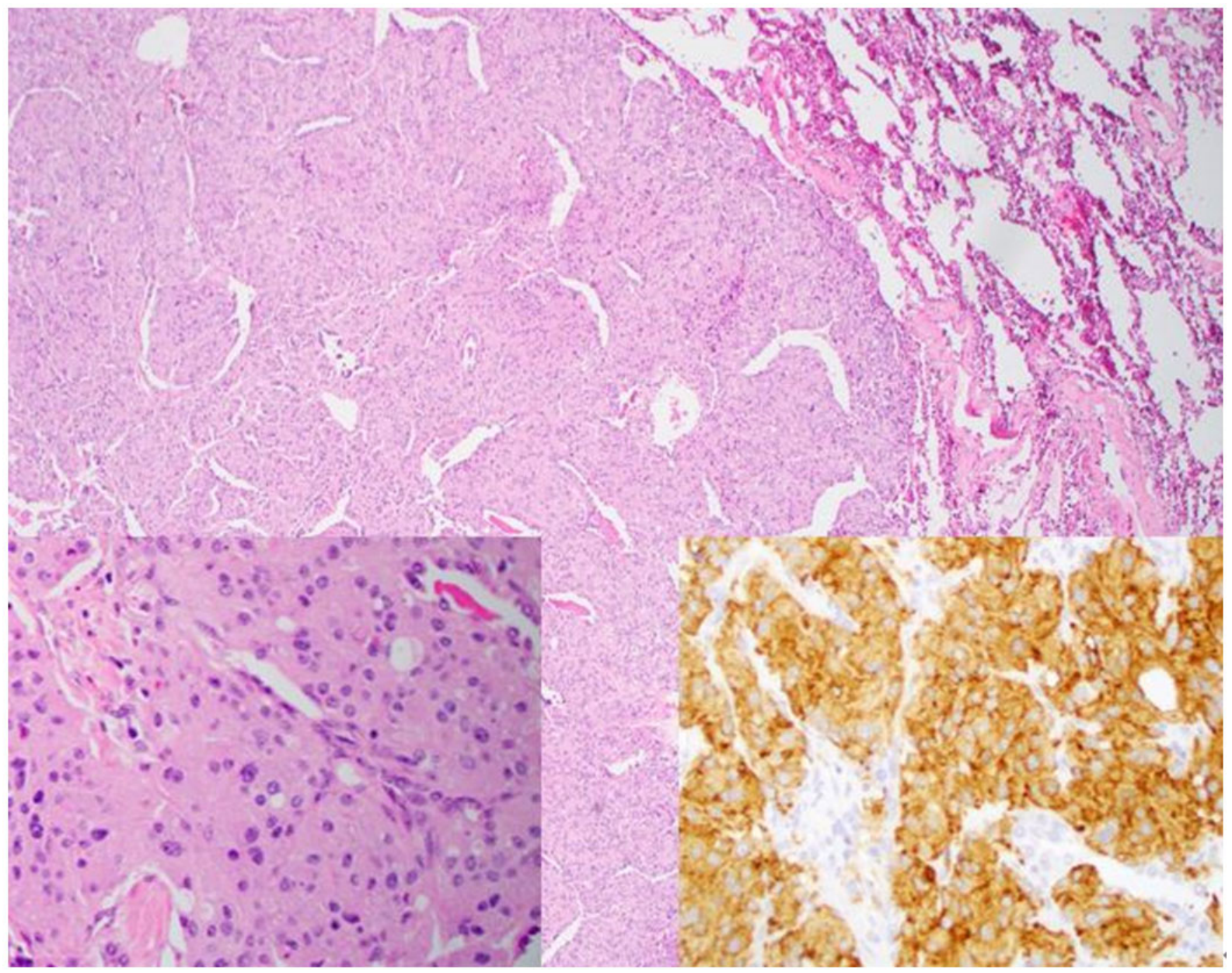

Figure 2. Metastatic paraganglioma in the lung, $x 4$ (left inset, x20; right inset- synaptophysin, $x 20$ )

\section{Discussion}

Although the exact incidence of benign paraganglioma and pheochromocytoma is unknown, an approximate incidence of 0.7 to 1.0 per 100,000 person-years has been reported, whereas, for malignant paragangliomas, a much lower estimated incidence of 90 to 95 per 400 million person-years has been described. ${ }^{[2,3]}$ The pathogenesis of paragangliomas remains incompletely understood. However, loss of function mutations in the genes encoding the succinate dehydrogenase subunits or cofactors, and the proteins associated with oxidative phosphorylation in the mitochondria have been demonstrated to occur in sporadic and hereditary paragangliomas. ${ }^{[4]}$ Though largely unknown, the exact mechanism of tumorigenesis is likely to be related to metabolic alteration at the cellular level. ${ }^{[5-7]}$

Paragangliomas usually develop in two locations. One common site is around the great vessels of the head and neck; the prototype of this group is the carotid body tumor. The second location involves the paravertebral paraganglia and among this group, the bladder is a rare site of occurrence. Tumors in the paravertebral group are chromaffin positive. Morphologically, paragangliomas show a zellballen pattern of cells with regular oval to round nuclei with vesicular chromatin and abundant pale granular eosinophilic cytoplasm. Nuclear pleomorphism and mitotic figures are typically rare. 
Immunohistochemical staining of these tumor cells demonstrates positivity for neuroendocrine markers like chromogranin, synaptophysin, CD56, CD57, and neuron-specific enolase. Immunohistochemistry for cytokeratin is negative, and this differentiates the tumor from neuroendocrine tumors including carcinoid and small cell carcinoma. GATA-3 is typically positive, and this feature may result in a bladder paraganglioma being misdiagnosed as urothelial carcinoma. ${ }^{[8]}$ The surrounding supportive fibrovascular stroma in paragangliomas is composed of spindle-shaped cells known as sustentacular cells, and this may be highlighted by positive staining with S-100 protein.

Metastasis in paragangliomas is the tumor occurrence in nonchromaffin tissue and is associated with a mutation in the SDHB gene. The risk for metastasis is reportedly higher in patients less than 35 years, primary tumors greater than $5.0 \mathrm{~cm}$, and tumors producing only norepinephrine..$^{[1,9,10]}$ The index case had a bladder primary which was $5.8 \mathrm{~cm}$ at resection without any evidence of metastatic disease at the time of diagnosis. The patient had a markedly elevated blood normetanephrine level, with normal metanephrine levels. The positive SDHB gene mutation in the patient warranted close surveillance post resection of the primary tumor with detection of a pulmonary nodule within one year of complete resection of the primary. There is no clear-cut factor for predicting the clinical course of heredofamilial paragangliomas, as standard neoplastic features such as nuclear pleomorphism, mitosis, or vascular features such as invasion are unreliable indicators of prognosis. In addition to a higher risk for metastatic paraganglioma in patients with SDHB gene mutation, these patients have a higher risk for other tumors such as SDH-deficient gastrointestinal stromal tumors, as well as SDH deficient renal cell carcinoma. SDHB immunohistochemistry may be useful as a first line screening test to identify individuals who will benefit from germline testing, genetic counseling, and post-resection surveillance.

As much as 30\%-40\% of paragangliomas and pheochromocytomas are linked with genetic inheritance. ${ }^{[11]}$ The associated genes include the rearranged during transfection (RET) protooncogene, the Von Hippel Lindau (VHL) tumor suppressor gene, the neurofibromatosis type 1 (NF1) tumor suppressor gene, the gene that encodes the succinate dehydrogenase (SDH) complex subunits (A, B, C, and D) as well as the gene encoding the flavination enzyme for the succinate dehydrogenase A subunit (SDHAF2). Additionally, the kinesin family member $1 \mathrm{~B} \beta(\mathrm{KIF} 1 \mathrm{~B} \beta)$, PHD2, MYC-associated factor X (MAX), TMEM127, and hypoxia-inducible factor $2 \alpha$ (HIF2A), are all associated with pheochromocytoma/ paraganglioma development. ${ }^{[4]}$ SDHx-related tumors overexpress specific genes involved in the transport of proteins, energy metabolism, transcriptional regulation, proliferation, and cell adhesion. Specifically, in SHDB-related paragangliomas, certain genes such as LGR5, SIX1, MMP24, DSP, and LAPTM4B, which are essential in the development of metastasis, have been identified. ${ }^{[12]}$ Paragangliomas with SDHB mutation are associated with an incidence at a younger age, aggressive course, extra-adrenal primary tumors, metastasis, and ultimately, poor prognosis. ${ }^{[13]}$

\section{Conclusion}

There is a higher risk of the development of metastatic disease in extra-adrenal paragangliomas occurring in the setting of heredofamilial syndromes, even after complete resection of the primary tumor with negative surgical margins. Ultimately, lifelong surveillance is strongly warranted in such patients for the detection of metastatic lesions and the prevention of possible complications.

\section{CONFLicts OF InTEREST Disclosure}

There is no conflict of interest.

\section{REFERENCES}

[1] Timmers HJ, Kozupa A, Eisenhofer G, et al. Clinical presentations, biochemical phenotypes and genotype-phenotype correlations in patients with succinate dehydrogenase subunit B-associated pheochromocytomas and paragangliomas. J Clin Endocrinol Metab. 2007; 92(3): 779-786. PMid: 17200167. https://doi.org/10.1210/ jc. 2006-2315

[2] Berends AMA, Buitenwerf E, de Krijger RR, et al. Incidence of pheochromocytoma and sympathetic paraganglioma in the Netherlands: A nationwide study and systematic review. Eur J Intern Med. 2018; 51: 68-73. PMid: 29361475. https://doi.org/10.1016/ j.ejim.2018.01.015

[3] Neumann HPH, Young WF, Eng C. Pheochromocytoma and Paraganglioma. N Engl J Med. 2019; 381(6): 552-565. PMid: 31390501. https ://doi .org/10.1056/NEJMra1806651

[4] Vicha A, Zdenek M, Pacak K. Genetics of pheochromocytoma and paraganglioma syndromes: new advances and future treatment options. Curr Opin Endocrinol Diabetes Obes. 2013; 20(3): 186-191. PMid: 23481210. https://doi.org/10.1097/MED.0b013e32 $835 f \operatorname{cc} 45$

[5] Pollard PJ, Briere JJ, Alam NA, et al. Accumulation of Krebs cycle intermediates and overexpression of HIF1alpha in tumours which result from germline FH and SDH mutations. Hum Mol Genet. 2005; 14(15): 2231-2239. PMid: 15987702. https://doi .org/10.109 $3 / \mathrm{hmg} /$ ddi227

[6] Selak MA, Armour SM, MacKenzie ED, et al. Succinate links TCA cycle dysfunction to oncogenesis by inhibiting HIF-alpha prolyl 
hydroxylase. Cancer Cell. 2005; 7(1): 77-85. PMid: 15652751. https://doi.org/10.1016/j.ccr.2004.11.022

[7] Dahia PL. Transcription association of VHL and SDH mutations link hypoxia and oxidoreductase signals in pheochromocytomas. Ann N Y Acad Sci. 2006; 1073: 208-220. PMid: 17102089. https://doi.org/10.1196/annals.1353.023

[8] So JS, Epstein JI. GATA3 expression in paragangliomas: a pitfall potentially leading to misdiagnosis of urothelial carcinoma. Mod Pathol. 2013; 26; 1365-1370. PMid: 23599157. https://doi.or $\mathrm{g} / 10.1038 / \mathrm{modpathol} .2013 .76$

[9] Cho YY, Kwak MK, Lee SE, et al. A clinical prediction model to estimate the metastatic potential of pheochromocytoma/paraganglioma: ASES score. Surgery. 2018; 164: 511-517. PMid: 29929757. https : //doi.org/10.1016/j.surg.2018.05.001
[10] Fliedner SMJ, Lehnert H, Pacak K. Metastatic Paraganglioma. Semin Oncol. 2010; 37(6): 627-637. PMid: 21167381. https://doi.or $\mathrm{g} / 10.1053 / \mathrm{j}$.seminoncol .2010 .10 .017

[11] Gimenez-Roqueplo AP, Dahia PL, Robledo M. An update on the genetics of paraganglioma, pheochromocytoma, and associated hereditary syndromes. Horm Metab Res. 2012; 44: 328-333. PMid: 22328163. https://doi.org/10.1055/s-0031-1301302

[12] Burnichon N, Vescovo L, Amar L, et al. Integrative genomic analysis reveals somatic mutations in pheochromocytoma and paraganglioma. Hum Mol Genet. 2011; 20: 3974-3985. PMid: 21784903. https://doi.org/10.1093/hmg/ddr324

[13] Amar L, Baudin E, Burnichon N, et al. Succinate dehydrogenase B gene mutations predict survival in patients with malignant pheochromocytomas or paragangliomas. J Clin Endocrinol Metab. 2007; 92(10): 3822-3828. PMid: 17652212. https://doi.org/10.1 210/jc.2007-0709 